\title{
EU E A RUA: SER CRIANÇA EM SITUAÇÃO DE RUA NA CIDADE DE BRAGANÇA-PA.
}

\author{
Luis Costa Saraiva ${ }^{1}$ \\ Jéssica Do Socorro Leite Corrêa ${ }^{2}$
}

\begin{abstract}
RESUMO
O presente trabalho é resultado de pesquisa realizada com crianças em situação de rua nos anos de 2014 e 2015, na cidade de Bragança-PA, com o objetivo de verificar as circunstâncias que atraem as crianças à rua e que em muitas situações as tornam atores sociais vulneráveis a violência verbal, física e afetiva. O estar na rua possibilita situações de violência, maus tratos, abandono escolar e familiar, mas a rua também é uma fuga para aquelas que sofrem essas violências dentro de casa, nesse aspecto é necessário entender as circunstâncias vivenciadas por cada ator social que ocupa os espaços da rua na cidade de Bragança-PA. O objetivo da pesquisa foi descobrir o que realmente se passa nesse ambiente e quais as situações que implicam na permanência das crianças nas ruas, para isso foi necessário a aproximação da realidade a partir dos relatos e compreensão dos saberes desses sujeitos em evidência.
\end{abstract}

Palavras-chave: Criança. Rua. Infância. Bragança-Pará.

\begin{abstract}
The present study is a result of research carried out with street children in the years 2014 and 2015, in the city of Bragança-PA, in order to verify the circumstances that attract children to the street and in many situations make them Social actors vulnerable to verbal, physical and emotional violence. Being on the street makes possible situations of violence, maltreatment, school and family abandonment, but the street is also an escape for those who suffer these violence at home, in this aspect it is necessary to understand the circumstances experienced by each social actor occupying the spaces Of the street in the city of Bragança-PA. The objective of the research was to find out what is really going on in this environment and what situations involve the permanence of children on the streets, for this it was necessary to approach reality from the reports and understanding of the knowledge of these subjects in evidence.
\end{abstract}

Keywords: Child. Street. Childhood. Bragança-Pará.

Recebido em: 21/04/ 2017

Aprovado em: 10/05/2017

\section{INTRODUÇÃO}

O trabalho realizado com crianças em situação de rua surgiu do questionamento da existência de crianças nas ruas de Bragança-PA. A partir de então passamos a observar melhor o cotidiano das ruas e fazer leituras envoltas nessa discussão, como: Graue e Walsh (2003), Abreu (2010), Paica-Rua/org. (2006), etc. Assim iniciamos em 2014 e 2015 uma

\footnotetext{
${ }^{1}$ Doutor em Antropologia. Professor Adjunto FACED/UFPA, Campus de Bragança. Membro do grupo de Pesquisa e Estudos Socioambientais Costeiros (ESAC). Professor da Pós-graduação em Linguagens e Saberes na Amazônia/UFPA. E-mail: luisjsaraiva@yahoo.com.br

${ }^{2}$ Mestranda do Programa de Pós-graduação em Linguagens e Saberes da Amazônia / UFPA. Membro do grupo de Pesquisa e Estudos Socioambientais Costeiros (ESAC). E-mail: etieljessica@gmail.com
} 
pesquisa de campo nas principais ruas da cidade para acompanhar as vivências dessas crianças e com elas construir um diálogo que nos proporcionasse compreender a dinâmica da rua enquanto espaço de fuga, aprendizado e amparo socioeconômico.

De acordo com o levantamento Nacional $^{3}$ sobre o uso de drogas entre Crianças e adolescentes em situação de rua nas 27 capitais brasileiras (2003), apesar de existir diferenças entre as capitais brasileiras, em todas, segundo o levantamento, existem crianças e adolescentes em situação de rua, "essa constatação por si merece atenção, uma vez que no Brasil existe o Estatuto da Criança e do Adolescente (ECA) que prevê garantia de condições básicas para o desenvolvimento durante a infância e a adolescência” (pág. 16).

Foi a partir dessa questão que iniciamos a pesquisa com as crianças que vivenciavam o ambiente da rua e assim nos aproximamos de distintas realidades, que diferem nos caminhos que levam às ruas, mas que comungam dos saberes desse mesmo espaço de convivência, a rua. Crianças com uma grande bagagem de sonhos e responsabilidades, em uma vida cercada por uma sociedade preconceituosa e alheia às exigências legais direcionadas a elas.

A pesquisa foi realizada com 7 crianças em situação de rua, não foi possível acompanhar da mesma maneira todas elas e também os momentos de diálogo ocorreram em espaços diferenciados e que não puderam ser estabelecidos anteriormente, cada momento de aproximação ocorreu de forma aleatória, com exceção da única menina que sempre saía às ruas para pedir acompanhada de alguém (pai ou irmão), as conversas com ela aconteceram no ambiente escolar (antes das aulas, durante os intervalos ou em outros horários sem aula), as demais crianças eram meninos e nossa aproximação ocorreu em todos os momentos nas ruas.

Construímos um diagrama de apresentação a partir daquilo que as crianças nos falavam, para que o leitor também possa conhecer os atores sociais que nos auxiliaram no desenvolvimento da pesquisa. São eles:

\footnotetext{
3 Já foram realizados 5 levantamentos pela CEBRID (Centro brasileiro de informações sobre drogas psicotrópicas) nos anos de 1987, 1989, 1993, 1997 e 2003.
} 


\begin{tabular}{|c|c|c|c|c|}
\hline Nome fictício ${ }^{4}$ & Idade & Sonho & Medo & Por que tá na rua? \\
\hline Dora & 8 anos & Uma bicicleta & Do escuro & Fome \\
\hline Pirulito & 9 anos & Jogador de futebol & Conselho tutelar & Ajudar em casa \\
\hline Barandão & 10 anos & Ser policial & Conselho tutelar & $\begin{array}{c}\text {-Ajudar em casa; } \\
\text { - Pagar hora no vídeo } \\
\text { game. }\end{array}$ \\
\hline João Grande & 11 anos & Comprar casa para a avó & Nada & $\begin{array}{c}\text { - Ajudar em casa; } \\
\text { - Comprar merenda } \\
\text { na escola; } \\
\text { - Comprar roupa. }\end{array}$ \\
\hline Boa-vida & 9 anos & Comprar uma bola & Nada & $\begin{array}{c}\text { Não gosta de ficar } \\
\text { em casa }\end{array}$ \\
\hline João de Adão & 12 anos & - & - & - \\
\hline
\end{tabular}

As crianças que acompanhamos durante a pesquisa tinham uma família, apesar de alguns tivessem uma relação conflituosa, apenas Dora, Pirulito, Barandão e João Grande retornavam para casa depois de pedir ajuda nas ruas. João de Adão foi a criança que apenas observamos de uma determinada distância, pois ele evitava aproximação e o tempo de pesquisa foi insuficiente para criar uma proximidade, entretanto, conversamos com uma psicóloga que o acompanha desde os 5 anos de idade, momento em que ele já frequentava as ruas, ela nos relatou ${ }^{5}$ que ele já não retorna mais para casa a bastante tempo, e também que ele já é usuário de drogas e aviãozinho ${ }^{6}$.

Considerando o aspecto pontuado anteriormente de uma organização temporal suficiente para pesquisa, é válido ressaltar que o trabalho com crianças exige um primeiro momento de aproximação dos atores sociais, em outras palavras, a organização espacial de aproximação e proximidade. Em 12 meses de pesquisa, podemos afirmar que o ambiente de interação entre pesquisadores e crianças ainda não estava tão firme quanto deveria, levando em conta a facilidade em relatar alguns acontecimentos e a timidez que demonstrava a maioria.

Boa-vida é outro menino que não retorna com frequência para sua casa, durante nossas conversas ele afirmou não gostar de sua família, pois suas irmãs eram “chatas" e sua mãe não demonstrava se importar com ele, e nos contou ainda sobre sua experiência de dormir nas ruas, lembrando uma situação ruim:

\footnotetext{
${ }^{4}$ Os noms fictícios foram escolhidos a partir dos personagens do romance de Jorge Amado (2009), Capitães da areia, a escolha não foi intencional e não se trata de uma comparação de comportamento ou características, a escolha foi aleatória.

5 Anotações em diário de campo em: 29/06/2014

${ }^{6}$ No jargão policial significa a pessoa que leva o tóxico para um comprador e volta com o dinheiro para o traficante dono da droga (de acordo com o dicionário online em www.dicionarioinformal.com.br).
} 
Minha mãe é faxineira, tenho três irmãs e mais um irmão que o pai dele abandonou ele quando ele era piquixito, ainda tava na barriga da minha mãe. Eu já passei um bocado de vez fome (...) eles me xingavam e minhas irmãs brigam muito aí as vezes eu fico na rua. Ai eu fui dormir num papelão que estava no chão, ai o mendigo disse que era dele e me xingou. ${ }^{7}$

Não necessariamente a lembrança apresentada por Boa-vida estava relacionada a um medo, pois quando perguntamos sobre o medo ele afirmou não ter nenhum, mas com relação a uma dificuldade que já vivenciou ele nos apresenta, conforme supracitado, a "disputa" por local e material de dormida.

Conhecer um pouco os atores sociais envolvidos na pesquisa nos leva a imaginar, a partir das situações que serão apresentadas, o que cada criança sente, aprende e vivencia, apesar do sentir estar relacionado a uma interpretação subjetiva, aqui ele também poderá ancorar sua significação no ato de refletir sobre o que é ser criança, como foi nossa infância e também como se constrói socioculturalmente o ser criança no contexto da rua.

Nessa perspectiva para o início do trabalho era necessário delimitar uma área de observação e interação, o que foi possível fazer no primeiro mês (julho 2014), mas essas crianças foram se deslocando no decorrer do desenvolvimento da pesquisa e a delimitação do espaço já não era mais válida. Eles não tinham um espaço fixo para pedir, estavam sempre em movimento, em lugares diferentes, foi preciso em muitos momentos sair a procura deles para criar e realizar um espaço de diálogo.

Procuro evidenciar neste artigo as questões que estão relacionadas às crianças e seu envolvimento com a rua, como: a violência, seus sonhos e medos. Considerando alguns autores importantes na discussão da pesquisa realizada com crianças, entre eles Cohn (2005) que é persistente nas suas colocações em relação à pesquisa com crianças e não sobre as crianças, e o caráter dialógico de uma observação participante, em que as crianças são tratadas pelo pesquisador em condições de igualdade, ouvindo delas sobre o que fazem e o que pensam sobre o que fazem.

Complementando com as contribuições de Corsaro (1985), "as crianças são capazes de inventar, em contextos criados pelos adultos, os seus próprios subcontextos, que permanece a maioria das vezes invisíveis para os adultos, mas que são bem visíveis e notórios para as crianças", assim é preciso fazer uma pesquisa longitudinal, em que seja possível estar tanto o adulto quanto a criança na mesma direção, estando o pesquisador para além de um adulto típico, estando sensível a tudo o que é dito, ficando assim atento às diversas situações que poderão vir a acontecer.

\footnotetext{
${ }^{7}$ Anotações em diário de campo em: 06/12/2014
} 
"A observação participante pode ainda ser complementada com outros recursos, tais como coleta de desenhos e histórias elaboradas pelas crianças" (COHN, 2005, p. 45), assim paralelo as contribuições teóricas, conciliamos a metodologia da produção de desenho realizado com as crianças. A atividade foi realizada apenas Barandão, Pirulito e João Grande, o objetivo da atividade era que as crianças pudessem apresentar situações da rua e coisas que gostam a partir de seus próprios traços, com Dora disponibilizamos materiais de desenho para que ela pudesse levar para casa e desenhar livremente o que desejasse. Nessa perspectiva consideramos que o desenho proporciona um mergulho leve naquilo que vivenciamos e pode ainda vir estruturado de maneira fantasiosa, Oaklander (1980) destaca que a fantasia funciona enquanto um mecanismo e até mesmo um processo psicossocial, considerando a fantasia enquanto uma projeção, transformação e interpretação daquilo que se deseja representar.

\section{A RUA}

O contexto de pesquisa é a rua, e com a observação da movimentação social e estrutural verificou-se que ela é um espaço utilizado por essas crianças com o propósito de arrecadar recursos financeiros, mas também é um lugar para se divertir, interagir com os colegas e principalmente brincar, afinal essa é a melhor parte da infância, independente da situação vivenciada elas criam seus próprios "subcontextos" (CORSARO, 1985), e em diversas situações eles pareciam ignorar o que estava ao seu redor, principalmente os olhares desconfiados e mal-humorados dos adultos.

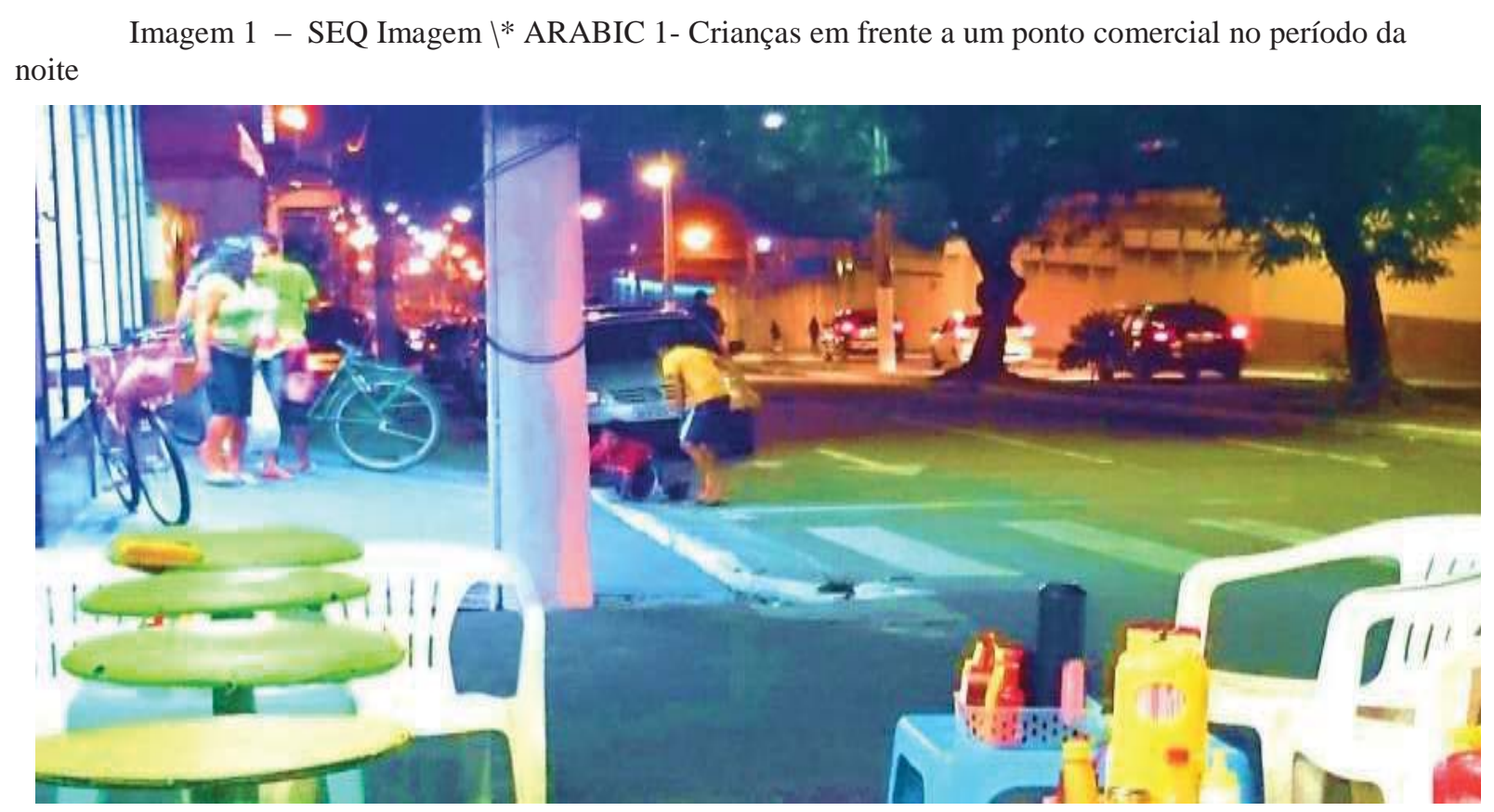


Imagem 2 - Crianças na Orla da Cidade no período da tarde

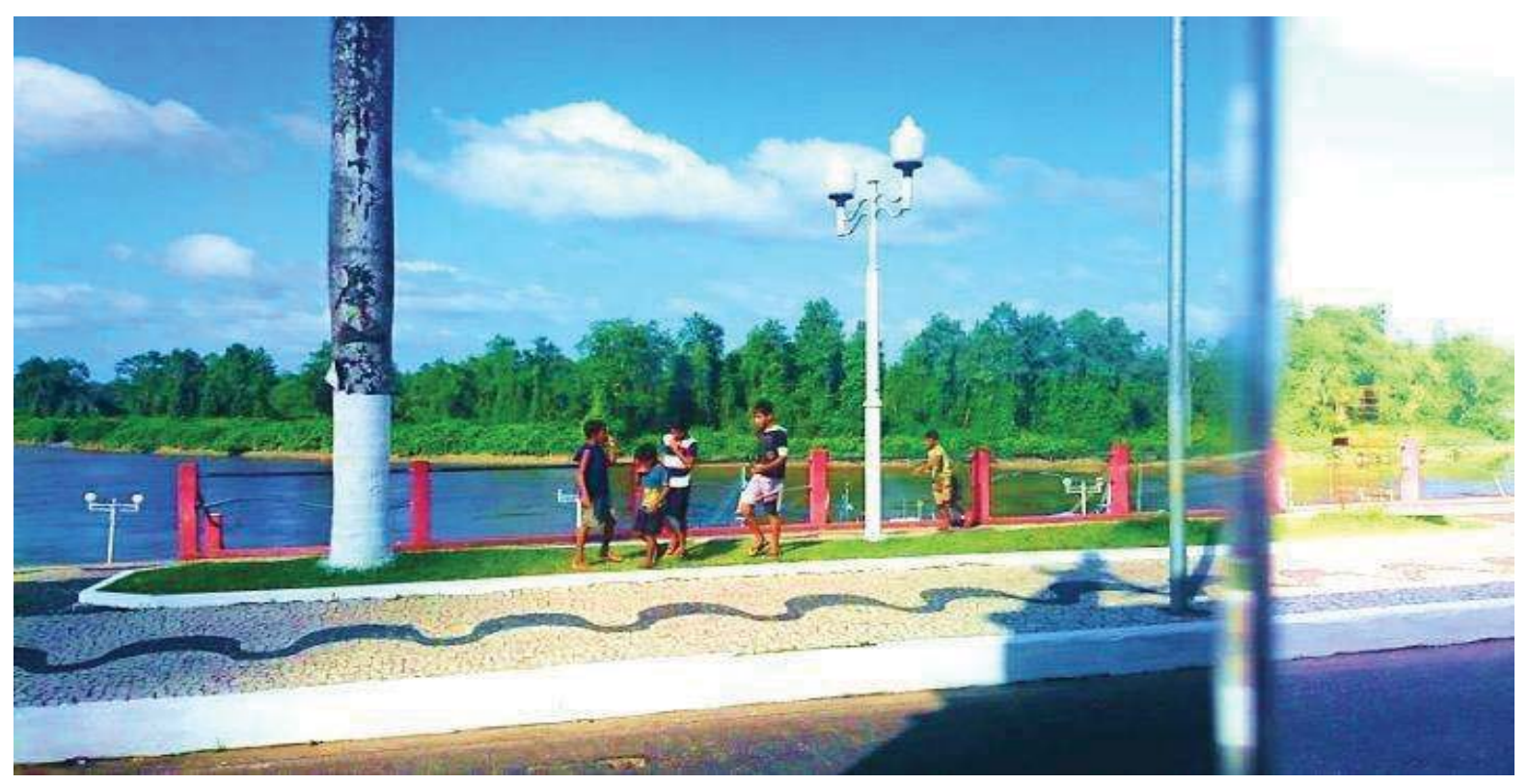

No início da pesquisa acompanhamos situações diversificadas, acompanhando distanciadamente o

movimento das crianças, a exemplo do momento em que dois garotos estavam em frente a uma farmácia pedindo ajuda para as pessoas que entravam naquele ponto comercial, até que alguém saiu e deu a eles umas moedas, e na tentativa de guardá-las no bolso, as moedas caem no chão e escorregam até a fresta do esgoto, com isso eles iniciam a competição do resgate da moeda, cada um tem sua vez de tentar e depois de algumas tentativas recuperam a "fugitiva". Outro registro aconteceu no período da tarde, os dois garotos que estavam na situação anterior também agora compartilhavam com mais três colegas de uma tarde divertida com pedaços de papelão, em que podiam utilizá-los para escorregar na grama da Orla da cidade.

Todo esse conjunto de imagens nos apresenta o quanto estamos cercados por pequenos trabalhadores, ou melhor, crianças que desde sua tenra infância experimentam a rua e se relacionam com ela de todas as formas possíveis e imagináveis, essa situação não é uma realidade do século atual.

\section{O BRINCAR}

As imagens 1 e 2 foram registradas durante as observações que ocorreram no mês de julho, próximo a Praça das Bandeiras e na orla da cidade, respectivamente. $\mathrm{Na} 1^{\mathrm{a}}$ as crianças a partir de uma determinada situação elas começaram a brincar e disputavam quem pegava a 
moeda. O segundo registro aconteceu no momento em que eles tinham acabado de brincar escorregando na inclinação da orla e saíram em direção a outra praça.

Nesse aspecto quando pensamos em crianças, inevitavelmente, pensamos no brincar e as crianças que estão em situação de rua também apreciam esse momento da infância, o que é primordial para o seu desenvolvimento e de grande valia no aprendizado, "brincadeiras são como rituais que se transmitem, repetidos ou recriados, em ambientes socioculturais distintos" (CARVALHO e PONTE, 2003. p.16). Entretanto, nós que estamos externos a essa situação ou que não identificamos esses sujeitos enquanto crianças e sim como "pedintes" ou até mesmo "delinquentes" em potencial, passamos por desconsiderar os aspectos fundamentais dessa fase humana do desenvolvimento, o brincar. Nesse sentido é válido ressaltar que tanto os aspectos cognitivos quanto os sociais do brincar são influenciados pelos ambientes que os adultos criam para as crianças e também os ambientes (trans)formados por elas.

A palavra alemã spilem (brincar e representar) de acordo com as reflexões de Bejamim (1994, p. 253) nos apresenta a síntese do brincar, "a essência da representação, assim como da brincadeira, não é "fazer como se", mas "fazer sempre de novo", é a transformação em hábito de uma experiência devastadora". Que em algumas circunstâncias configura-se enquanto representação do que é vivido socioculturalmente outras não, trata-se portanto da interação das crianças com o contexto que vivencia e seus pares.

A partir disso percebemos as contribuições sociais e culturais no processo de desenvolvimento das crianças. E quando nos referimos a pesquisa em questão, temos a rua enquanto espaço de aprendizado, utilizado por crianças de baixa renda para o divertimento e interação social, construindo assim modos de significação do mundo. Sem desconsiderar que em alguns momentos a interação das crianças em situação de rua com outras crianças em situação diferente acontece, a exemplo disso, descrevo uma situação que observei em uma noite de novembro no centro da cidade, havia um homem e uma criança sentados na mesa em frente a um restaurante, provavelmente pai e filho, a criança estava com um tablet na mão, aparentemente jogando, pois fazia movimentos constantes e algumas vezes rápidos no aparelho, o adulto que o acompanhava estava manuseando o celular, aparentemente distraído, quando se aproxima um garoto, João de Adão, que estava abordando as pessoas (pedindo ajuda), na praça em frente (local em que estávamos observando), ao chegar na mesa ele se direciona ao garoto e se coloca ao seu lado, ambos começam a interagir, conversam (provavelmente sobre o jogo) e também compartilham o aparelho e consequentemente o jogo, a brincadeira. As crianças interagem bem compartilhando daquela brincadeira e o adulto torna-se um observador, não fez nenhuma interferência, somente observa atento ao que estava 
acontecendo, mas o encanto do momento foi interrompido quando o garçom chegou trazendo o pedido da mesa e começou a servir a refeição, o garoto recolhe seu tablet e João de Adão se levanta e segue.

Optamos por passar um considerável período de observação para acompanhar a dinâmica das crianças na rua, somente depois desse período começamos a nos aproximar, o primeiro contato aconteceu com três meninos de idades diferenciadas, ficamos atentos ao que eles faziam e percebemos uma certa padronização da dinâmica de espaço que eles utilizavam naquela situação, eles escolheram dois pontos comerciais para ficar pedindo na porta e depois de um período curto de tempo eles revezavam o local, como fazemos em um jogo de quadra ao inverter as posições, nos aproximamos quando os três foram para a frente do mesmo ponto comercial, com eles sentamos na calçada para conversar, o mais novo era quem mais dialogava conosco, tinha 9 anos, os demais estavam tímidos, mas respondiam às nossas perguntas, tinham 10 e 11 anos. Durante a conversa buscamos identificar de forma tranquila, enquanto pessoas que estavam ali para aprender com eles e que gostaria de saber como é estar na rua, como as pessoas se dirigem a eles, seus sonhos, medos, família, etc. Com o passar da pesquisa percebemos que a dinâmica espacial e temporal de organização desses garotos em situação de rua estava longe de seguir um padrão e também de ser dominada por nós, por isso foi preciso (re)construir a cada dia de pesquisa de campo as formas de abordagem e os locais para encontrá-los.

De modo geral, as conversas aconteciam com bastante tranquilidade, indagava algumas situações e eles falavam normalmente, entre elas o porquê de estarem nas ruas, quais eram suas vontades e o que faziam com o dinheiro arrecadado, se tinham irmãos, se frequentavam a escola, a pretensão era registrar o cotidiano dessas crianças e também formar uma aproximação inicial tranquila, esse cuidado foi imprescindível nos encontros seguintes, pois para saber mais era necessário antes estabelecer confiança. Embasado nessa perspectiva de aproximação inicial do pesquisador com os atores sociais em foco na pesquisa, o trabalho realizado com crianças precisa dessa etapa inicial, caso contrário ele não terá continuidade, segundo Graue e Walsh (2003, p. 20) "observar crianças e trazer dessas observações somente números (ou, pior ainda, números estandardizados) diz-nos muito pouco acerca das interações das crianças no seu quotidiano e leva-nos a acreditar que tais interações podem, de fato, ser reduzidas a números”. Para realizar a pesquisa indo além dos números a aproximação e interação foram primordiais.

\section{OS MEDOS}


Quando pensamos em medos, remetemos nosso pensamento a situações óbvias ou até mesmo aos nossos próprios medos. Logo no início da pesquisa não foi diferente, o que de imediato era perceptível é que as crianças que estavam nesse ambiente possivelmente tinham medo. Medo de quê? Poderiam ter medo de crianças maiores, de adultos e da violência de modo geral que pudessem acontecer a elas.

Com o desenvolvimento da pesquisa descobrimos que o medo da violência era maior de nossa parte, que observamos e sentimos isso vivenciando. Estávamos sentados na calçada com Pirulito, João Grande e Barandão, conversando sobre o cotidiano deles quando um garoto mais forte e alto, de aproximadamente 12 anos interrompeu nosso diálogo aos gritos e bofetadas, atacando João Grande, sem pensar muito no que poderíamos fazer diante daquela situação ou não, de imediato pedimos para que o garoto se retirasse e ele exaltado disse que nós não conhecíamos quem estava sendo agredido e continuou os ataques verbais, mais uma vez insistimos para que o garoto se retirasse, exclamando que a violência não resolve problema nenhum, até que o garoto parou com as agressões físicas e se retirou do espaço, mas não o fez calado. Passada a situação, ambos ficamos constrangidos, em seguida perguntamos aos meninos se aquela situação era comum, mas eles não comentaram nada a respeito. Somente em outros momentos de conversa com eles foi possível perceber que situações como essa eram comuns estando na rua.

Ao perguntar sobre o que na rua os deixava com medo, os dois menores disseram ter medo do Conselho Tutelar e ainda afirmaram que eles (conselheiros) haviam passado diversas vezes por nós durante a conversa, perguntamos como eles sabiam disso e eles afirmaram conhecer as placas dos carros que eles utilizam. Ainda sobre a ação do Conselho, eles afirmaram que nunca foram "pegos" por representantes deste, pois sempre que o carro se aproximava do local em que as crianças pudessem estar elas saiam andando, pois assim eles não tinham motivos para levá-los.

Alguns aspectos que envolvem o medo só ficaram visíveis com o decorrer da pesquisa, quando as crianças já se sentiam seguras em fazer seus relatos. Antes de iniciar o trabalho já percebia alguns garotos que experienciavam a rua cotidianamente, entre eles o João de Adão, minha pretensão era me aproximar dele para conhecer um pouco mais sobre sua vida, ele é um garoto bastante conhecido que vivencia o ambiente de rua desde os 5 anos de idade, e não tem a casa como espaço de retorno, a rua já é sua principal companhia.

Pois bem, durante uma conversa com Pirulito e Barandão, sentados em uma barraca de churrasco em uma praça conversamos enquanto comíamos churrasco, perguntamos se eles 
conheciam e/ou mantinham contato com o João de Adão, eles rapidamente disseram "a gente não gosta dele não, ele é muito ruim pra gente... quando ele vê a gente na rua, ele joga pedra, ele só gosta de fazer maldade... e... também ele já fuma" ${ }^{» 8}$. De acordo com o relato dos dois irmãos, eles evitam a aproximação com crianças que apresentam atitudes mais violentas e preferem andar sempre em grupo no período da noite.

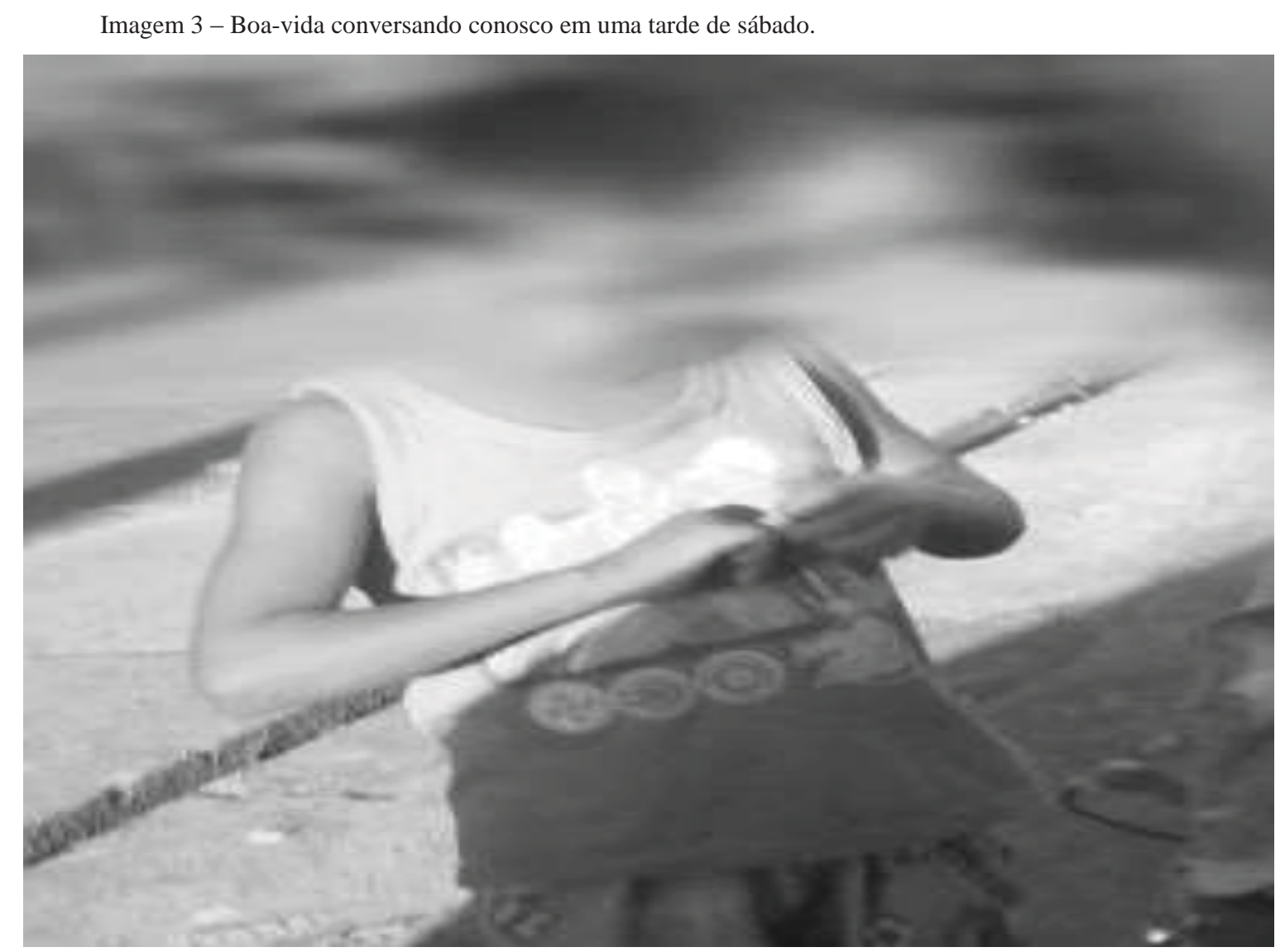

Entretanto, nem todas as crianças pesquisadas pensam assim, Boa-vida prefere ficar sozinho (9 anos), ele falou inclusive que já dormiu algumas vezes na rua e que não frequenta a escola, quando questionado sobre seus medos, ele disse que não tinha medo de nada, então perguntei sobre a violência nas ruas, ele contou a história de um dia que ele foi dormir na rua e foi expulso, do espaço que tinha escolhido para dormir, por um homem que morava na rua e se dizia dono daquele lugar. Sempre muito sério e direto em suas respostas, tudo o que perguntávamos era respondido de forma sucinta, apenas em alguns momentos ele nos olhava, na maioria das vezes preferia manter seu olhar voltado ao chão ou para suas mãos.

Outro garoto que também faz da rua a sua casa é João de Adão, muitas oportunidades tivemos de observá-lo, mas nada suficiente para garantir uma aproximação, umas dessas

\footnotetext{
${ }^{8}$ Anotações do diário de campo em 27/11/2014.
} 
oportunidades aconteceu quando andando pela orla da cidade em um dia de domingo encontramos ele com um rolo de fita preta, ele estava cercando com aquela fita os carros que estavam estacionados, quando chegamos perto ele disse: "o que foi? Esses carros são meus, vou reparar todinho eles", nossa reação no momento foi apenas dizer que estávamos apenas esperando alguém naquele local, então ele continuou a cercar os veículos e assim conseguimos registrar uma imagem do momento. Um ano após a pesquisa ele foi assassinado.

Imagem4: João de Adão no período da noite no domingo na Orla da Cidade

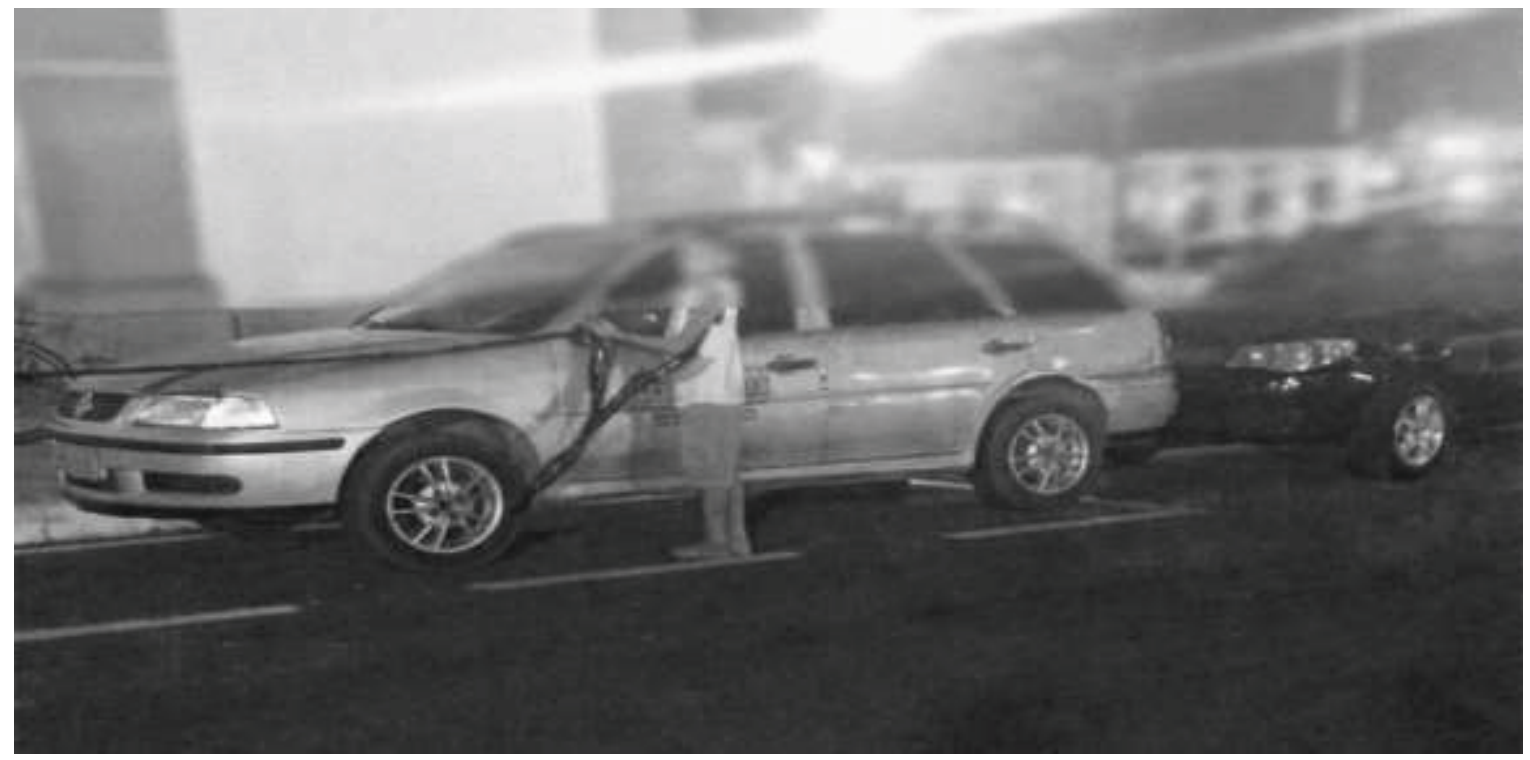

\section{UMA AJUDA?!}

Quando nos aproximamos de crianças em situação de rua, na maioria das vezes somos abordados com um pedido, em muitas situações observamos que os adultos querem ajudar somente com lições de moral que em um primeiro momento não tinham nenhum resultado positivo na realidade cotidiana das crianças em situação de rua.

O estar nas ruas, levando em consideração que a maioria das crianças pesquisadas têm uma relação familiar, retornam para uma casa, tem também o propósito de arrecadar um auxílio financeiro, nesse aspecto, conversamos com as crianças sobre o dinheiro que ganhavam, quando fizemos essa pergunta aos três garotos (Pirulito, Barandão e João Grande) que encontramos em frente a farmácia, consequentemente arrancamos deles sorrisos durante algumas respostas, possivelmente por imaginarem algum tipo de julgamento de nossa parte, mas no máximo nós retribuímos com mais sorrisos, em relação ao destino dado ao dinheiro, cada criança pontuou questões diferentes e também semelhantes, o que todos queriam era 
ajudar em casa, a mãe, a avó e/ou o pai a comprar comida, eles ainda apresentaram outras finalidades para o dinheiro arrecadado, destacaram principalmente: comprar roupas, calçados, comprar merenda na escola e pagar uma hora no videogame.

Eles falaram ainda de seus sonhos, do que queriam ser no futuro, e eles sempre pontuavam principalmente ajudar a família. Durante as conversas eles nos deram muito mais que palavras para responder as perguntas, pois o corpo também fala, e a maneira como seguravam suas próprias mãos nos chamou a atenção e fez imaginar que eles procuravam inibir gesticulações, a cabeça baixa e a voz leve, aspectos da timidez, essas características gestuais apareciam nas respostas mais sérias às perguntas mais diretas.

\footnotetext{
Ser um humano real, vivo, implica dispor de um tipo especial de aparência corporal, praticar certos tipos de comportamento comunicativo, e possuir certos estados de consciência (...). O 'eu' é tecido pela subjetividade [e] a intencionalidade é, ela própria, criada no contexto das relações sociais. [as relações sociais] são a condensação e a memória dos estados afetivos construídos pelas interações cotidianas que têm lugar nos processos de provisão do alimento, no compartilhamento e no trabalho. (TAYLOR, 1996 apud SILVA, 2002, p. 41)
}

Mesmo sem falar, se comunicar de forma oral, as pessoas o fazem pelo corpo, pelos gestos e também pelas expressões faciais, em algumas situações as pessoas não precisam nem abrir a boca para sabermos que estão tristes, assustadas, com raiva, etc. Entretanto para evitar equívocos é importante que elas nos falem sobre o que sentem e em algumas situações o porquê daquele sentimento para que seja possível compreender de fato. Na pesquisa optamos por observar gestos, mas também por perguntar sobre os sentimentos.

Nessa perspectiva indagamos aos garotos sobre suas vontades, eles com brilho nos olhos e com a empolgação de quem deseja realizar cada coisa que apresentam, e sempre com um sorriso no rosto, responderam aquela velha e famosa pergunta que todos fazem as crianças, o que eles desejavam ser quando crescerem. As respostas estão no quadro de apresentação inicial, ser policial e jogador de futebol (Barandão e Pirulito, respectivamente), mas também tem vontades de comprar uma casa para a avó (João Grande) ou ainda, como respondeu Boa-vida e Dora, comprar uma bola ou ter uma bicicleta.

As crianças que estão nas ruas e acabam por vivenciar os mais diversos tipos de situações, tem uma grande responsabilidade, pois caberá a eles fazer as escolhas para os (des)encantos que a rua oferece. A atitude dessas crianças para saírem às ruas em busca de auxiliar no sustento da família é um ato nobre que a sociedade se nega em reconhecer, mas que pode comprometer intensamente seu desenvolvimento e até atrapalhar a realização de seus sonhos. 
Através deste ganho fácil, é possível auxiliar na manutenção de sua família, tentar adquirir seus sonhos de consumo. Este ganho significa para esta criança, como modelos paternos fragilizados pela exclusão social, pelo desemprego, o afastamento do espaço da escola, a inversão de valores e o ônus trágico de suprimir do seu processo de desenvolvimento uma etapa tão importante: a infância. Nesse contexto deixamos de enxergar o "sujeito" por trás do pedido de "qualquer coisa" para, provavelmente, vermos um objeto, sem direitos, sem desejos. (PAICA - RUA, 2011. p. 26)

De acordo com essas questões é válido refletir sobre o que verdadeiramente as crianças procuram estando nas ruas, estruturando assim maneiras para a não contribuição negativa do estar na rua ao seu desenvolvimento, além de cobrar ações governamentais significativas para eliminar essa problemática ou transformá-la, entretanto o que poderia ser um caminho satisfatório para a solução dessa questão, faz-se o caminho contrário, procuramos descarregar nossa indignação com a situação em cima dos atores sociais que são os maiores prejudicados. Infelizmente esse tipo de situação torna as crianças objetos de mera observação.

Existe ainda certa indiferença a essas crianças, se alguém se aproxima e senta junto a elas na calçada ou em algum banco de praça e começam a conversar, essas pessoas passam a ser observadas pelos demais, a curiosidade sobre o que fazem, e o que conversam. Esses incômodos ocorreram no início da pesquisa, mas no decorrer da pesquisa conseguimos ignorar, assim como fazem as crianças.

As literaturas sobre o tema nos auxiliaram bastante na construção dessa pesquisa, pois diante da realidade das crianças em situação de rua, em muitos momentos precisamos ver a leveza dos fatos ou sua essência, daí mergulhamos na realidade apresenta por Jorge Amado (1937) dos Capitães de Areia, que nos apresenta a dinâmica de vida de um grupo de crianças e adolescentes em situação de rua, em seus saberes, conflitos, histórias e desejos. "Porque naquelas casas, se o acolhiam, se lhe davam comida e dormida, era como cumprindo uma obrigação fastidiosa. Os donos da casa evitavam se aproximar dele, e o deixavam na sua sujeira, nunca tinham uma palavra boa para ele (...)”. (AMADO, 1937. p. 118-119) 
Imagem 5 - Pedindo ajuda em uma ensolarada manhã de domingo.

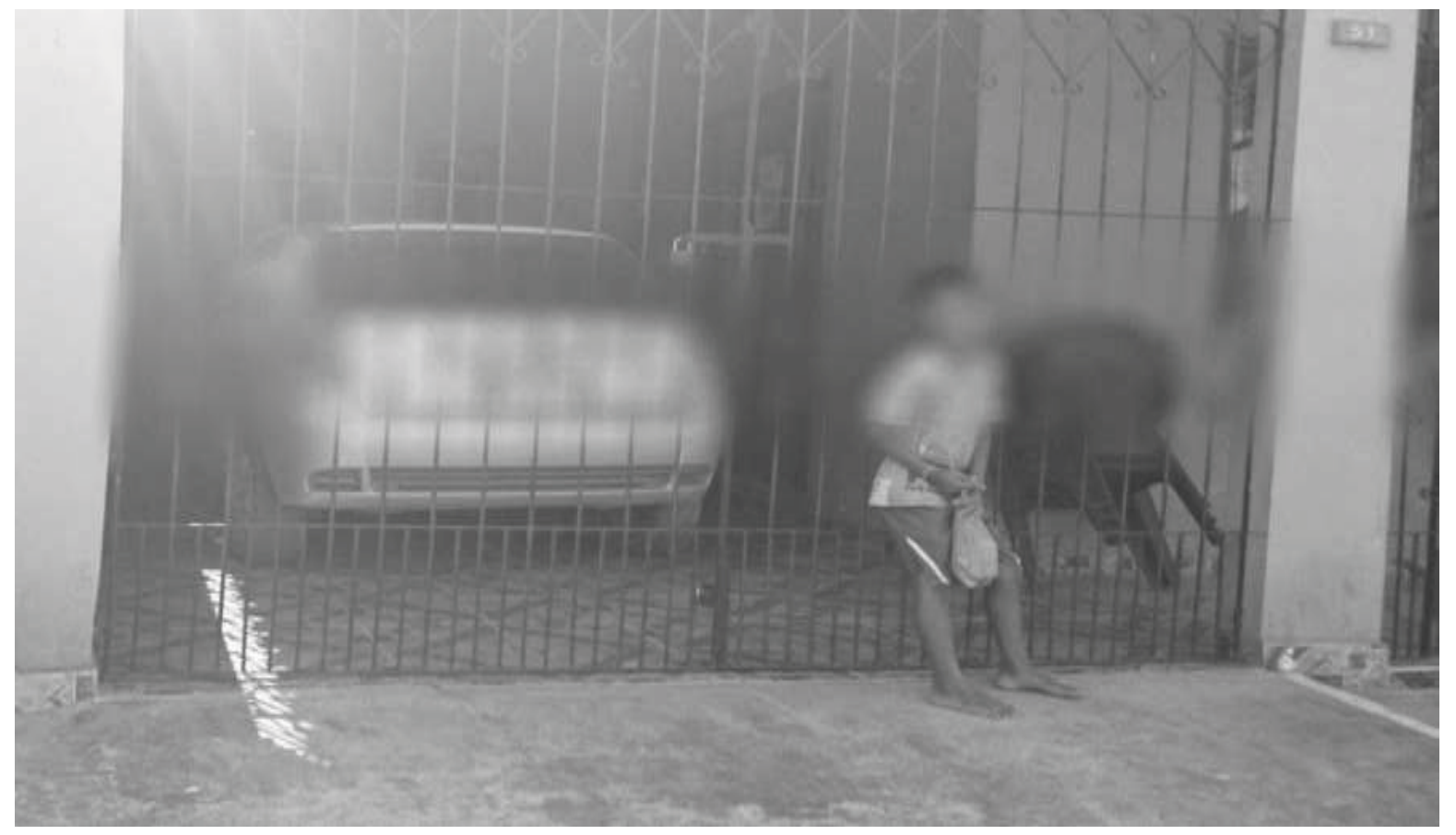

O estar na rua proporciona negativamente a essas crianças um olhar estigmatizado de uma sociedade que cobra soluções, mas que não deseja contribuir para tal, uma contribuição significativa e satisfatória. No trecho de Jorge Amado (1937), fica evidente o que percebemos cotidianamente ao pesquisar crianças em situação de rua, o ato de ajudar as crianças que solicitam ajuda, em alguns casos, é apenas como cumprimento de uma obrigação ou até mesmo a maneira mais rápida de se livrar da situação. Existe ainda o ato de ignorar, como na imagem anterior, a criança passa um tempo na frente da residência, chamando por alguém que não aparece.

É difícil classificar qual das situações é a pior, ou a mais dolorosa para quem observa, pois para quem vive isso é comum, Pirulito pedia ajuda em uma bela manhã de domingo, momento em que coincidentemente o encontrei, a rua estava praticamente vazia, apenas ele embelezava aquele ambiente quente e solitário. Já estava se aproximando o horário do almoço, e na sua sacola aquilo que possivelmente iria alimentá-lo juntamente com sua família.

Sobre esse dia foi possível refletir acerca daquele garoto, muitos questionamentos surgiam e era preciso ser paciente para conseguir as respostas. Logo de início definimos que nossa aproximação seria restrita às crianças, para que o objetivo inicial de compreensão da relação delas com a rua não fosse desviado, mas os questionamentos nos sufocaram e foi preciso buscar por respostar, algumas coisas não se encaixavam devidamente, considerando que estava buscando a compreensão daquilo que observávamos dos fatos, assim conhecer a 
família desses garotos fez-se necessário.

$\mathrm{Na}$ maioria das vezes que encontramos as crianças elas estavam pedindo dinheiro, e estas já haviam falado sobre o destino dos valores arrecadados, entretanto encontramos Pirulito e Barandão em uma situação diferenciada, eles tinham nas sacolas que carregavam itens alimentícios, daí chegamos a conclusão que somente conhecendo essa família seria possível estabelecer uma conexão entre os fatos.

\section{A FAMÍLIA}

Para compreender melhor algumas informações dadas pelas crianças e até mesmo identificar suas reações diante do que se apresentava a elas, foi preciso conhecer a família, mas o tempo de pesquisa era pouco, por isso nós direcionamos nossa atenção para conhecer apenas a família de duas crianças que eram irmãos, Pirulito e Barandão.

Consegui descobrir o endereço dos garotos através de João Grande, e fomos visitá-los era uma manhã de sábado. Eles estavam em casa, juntamente com toda a sua família, sua mãe aparentemente com seus 37 anos com seu filho recém-nascido (21 dias) nos braços, o padrasto, aproximadamente 35 anos, com uma cara pálida, magro e que estava se recuperando de uma pneumonia, de acordo com os relatos da mãe, e juntamente com Pirulito e Barandão estavam seus outros 3 irmãos assistindo televisão.

A mãe nos contou que a família veio de outro município a pouco tempo em busca de emprego nesta cidade, ela acabou engravidando e ficou impedida de trabalhar com o nascimento da criança e seu esposo fazia alguns trabalhos para sustentar a família, mas passou alguns meses internado, tinha pegado pneumonia e ainda estava em processo de recuperação, eles moram em uma casa que pagam R $\$ 250,00$ de aluguel e no momento estão sobrevivendo somente com o dinheiro que ela recebe do Bolsa família das Crianças, valor esse que é direcionado quase todo para o pagamento do aluguel.

Nesse momento todos os conhecimentos sobre os direitos dessas crianças, as inquietações da sociedade para solucionar problemas, tudo o que até então escutamos, lemos e observamos, tudo o que até o momento foi edificado e construído com a pesquisa, nesse instante acabava de tomar uma força extra de caráter organizacional da sociedade, em que somos todos frutos de uma ideologia que cada vez mais exclui uma parcela significativa da sociedade, colocando estes a margem de seus direitos, encostados a sorte da sobrevivência. 
paradas temporárias e transitórias. O que define essas crianças não é necessariamente a falta de família ou de vínculo familiar, mas a circulação, o não se fixar em lugar nenhum. Isso não deve diminuir a gravidade de algumas experiências familiares traumáticas, mas significa que, antes de se assumir que estão nas ruas porque não têm família (...), deve-se ver de perto, e a partir da criança, que relação estabelece ou deixa de estabelecer com sua família, e como ela se constitui. (COHN, 2005. p. 32)

Considerando que o espaço da rua é mais um local de circulação das crianças e considerando as questões pontuadas por elas no decorrer da pesquisa, relacionamos o estar na rua interligando-se a sensação de liberdade, pois ir para a rua algumas vezes torna-se uma fuga da realidade, vivenciada por crianças que buscam espaços alternativos para vivenciar sua infância ${ }^{9}$ ou até mesmo estruturam os espaços que lhes são oportunos em determinadas situações, como é o caso da rua.

\section{O ENCANTO DA RUA}

João José, o Professor, desde o dia em que furtara um livro de histórias numa estante de uma casa da barra, se tornara perito nestes furtos. Nunca, porém, vendia os livros, que ia empilhando num canto do trapiche, sob tijolos, para que os ratos não os roessem. Lia-os todos numa ânsia que era quase febre. Gostava de saber coisas e era ele quem muitas noites, contava aos outros histórias de aventureiros, de homens do mar, de personagens heróicos e lendários (...) Contando aquelas histórias que lia e muitas que inventava, fazia a grande e misteriosa mágica de os transportar para mundos diversos, fazia com que os olhos vivos dos Capitães da Areia brilhassem como só brilham as estrelas das noites da Bahia. (AMADO, 1937)

O trecho do romance de Jorge Amado ilustra nesse momento as questões voltadas à liberdade para as crianças em situação de rua, a rica imaginação e a habilidade com a leitura do Professor proporciona ao grupo um veículo de fuga da vida na rua, o que os distancia das dificuldades do cotidiano e proporciona aos capitães uma viagem pelo mundo mágico das histórias contadas. Aquelas histórias aqueciam os corpos dos capitães de areia nas noites frias da Bahia, assim como garantia a eles asas para voar de tudo aquilo que poderia prendê-los a algum tipo de sofrimento.

Para as crianças da pesquisa não é diferente, essas asas da liberdade são proporcionadas por situações diversas em que elas largam ao chão tudo aquilo que pesa em seus ombros para que o vôo seja leve e tranquilo. Relacionamos as asas todas as situações que

\footnotetext{
${ }^{9}$ Para Ariès (1978) a particularidade da infância não será reconhecida e nem praticada por todas as crianças, pois nem todas vivem a infância propriamente dita, "esse sentimento da infância pode ser ainda melhor percebido através das reações críticas que provocou: (...) algumas pessoas rabugentas consideravam insuportável à atenção que se dispensava, então, às crianças (...)". (ARIĖS, 1978, p. 159). Arroyo (2011, p.179) ressalta que quando tentamos reconhecer a infância como tempo de direitos nos deparamos com uma visão tão inferiorizada que fez com que seu lugar na diversidade de espaços sociais fosse limitado aos espaços de proteção, cuidado e assistência.
} 
proporcione leveza, toda ação que estimule, nesse caso, o ser crianças, como é o caso das brincadeiras. Algumas crianças pesquisadas nos repassam também esse ar mais leve com seus sorrisos e seus olhos que encantam, sorriso que ilumina e proporciona, aos que se permitem, uma reflexão sobre o que somos, o queremos e como estamos situados mentalmente e fisicamente nessa sociedade cada vez mais egocêntrica.

Essa liberdade, do estar na rua, também foi percebida durante a conversa com Dora (9 anos), ela é uma menina bastante comunicativa e quando começa a conversar fala de muitas coisas ao mesmo tempo, é preciso estar atento para registrar informações que ela deixa solta principalmente em relação a sua vivência na rua. Na rua Dora está sempre acompanhada de seu pai que fica de longe esperando ela bater de porta em porta pedindo ajuda, minha aproximação dela aconteceu no ambiente da escola em que ela estuda e com a convivência ela foi relatando situações vivenciadas por ela na rua, sonhos e pesadelos.

(...) ai en fui na casa dos outros, acabou a comida e ew fui na casa dos outros, e eu fui... e... o que é piquena, ein?! Pode tirar esses pés imundo da minha casa! (...) (Nesse trecho ela faz uma voz diferente). Nós ia na rua pra pedir, ai eu falei, me ajuda eu não tenho nada na minha casa eu tô passando muito fome, ai me deram um prato de comida, eu comi, enchi a barriga, cheguei com a barriga em casa e a mamãe ficou com a barriga seca, ai o papai foi na rua arrumar umas coisas, tosse pra dentro de casa, (...) o conselho tutelar, foi lá em casa, a poliça, ai todo mundo chegaram lá em casa, deram ajuda pra gente, ponto, mas agora eu não to mais na casa dos outro pedindo 10 . (grifo nosso)

Ela nos apresenta muitas informações no decorrer de seu relato, mas destacamos dois aspectos importantes: a maneira como ela relata a forma como já chegou a ser tratada (negrito) e também a preocupação que ela ao final da fala tem em deixar claro para nós que ela não faz mais isso. Com o decorrer do trabalho com Dora e a partir das informações e dos desenhos confeccionados pela menina percebemos que a sensação de liberdade também se faz presente nela, a rua é um amplo espaço que ela pode explorar e expandir seus conhecimentos, pois em casa estará voltada complentamente aos cuidados da irmã caçula (8 meses) e dos três irmãos menores.

\footnotetext{
${ }^{10}$ Entrevista com Dora realizada em: 13.11.2014. (A escrita está de acordo com a fala de Dora)
} 

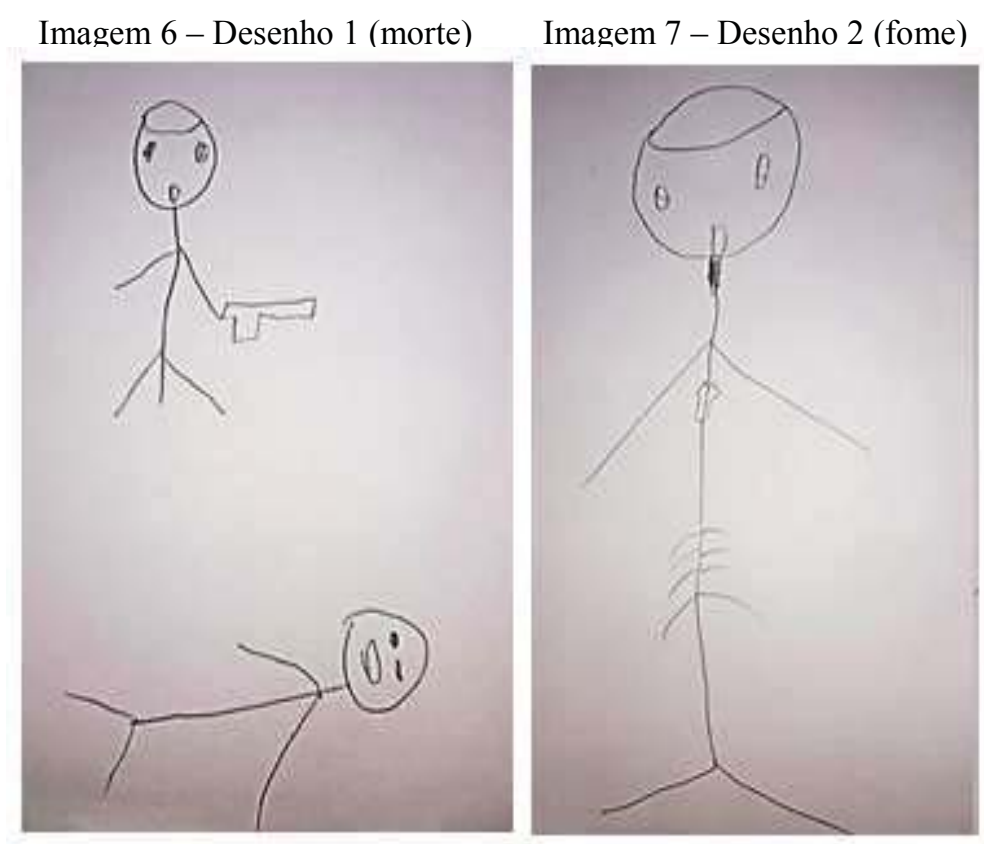

Imagem 8 - Desenho 3

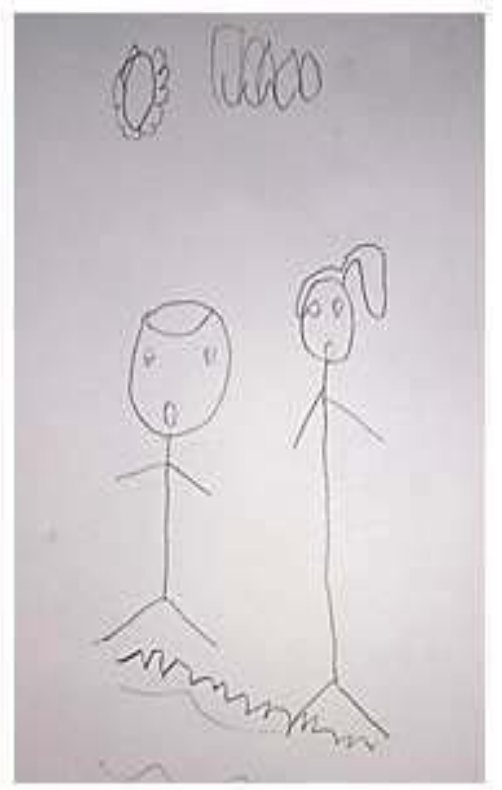

Quando falou sobre seus desenhos, Dora explicou cada um deles, falou do homem que matava outro, da fome que esse homem sentia, por isso aparecia suas costelas e também a apresentou e o irmão brincando em um dia de sol. Ela optou por não colorir os desenhos e também por não identificar quem ela desenhou nas imagens de fome e de violência. Em relação aos aspectos fantasiosos das criações infantis Oaklander (1980, p. 26), pontua ser importante levar em consideração as fantasias das crianças, pois estas são expressões de seus sentimentos, "as crianças constroem um mundo de fantasia por que julgam seu mundo real difícil de viver".

Outra representação feita pelas crianças a partir do desenho foi com relação a forma como as pessoas as recebem em algumas situações, Pirulito e Barandão também preferiram fazer rabiscos bem pequenos daquilo que é estar na rua para pedir. A escrita também é menor quando representam aqueles momentos que não tem ajuda.

Em contrapartida a representação daquilo que vivenciam nas ruas, Pirulito e Barandão não hesitam na utilização das tintas e dos pincéis para representar aquilo que gostariam de ter, suas vontades e gostos. 
Imagem 9 - Desenho feito por Barandão

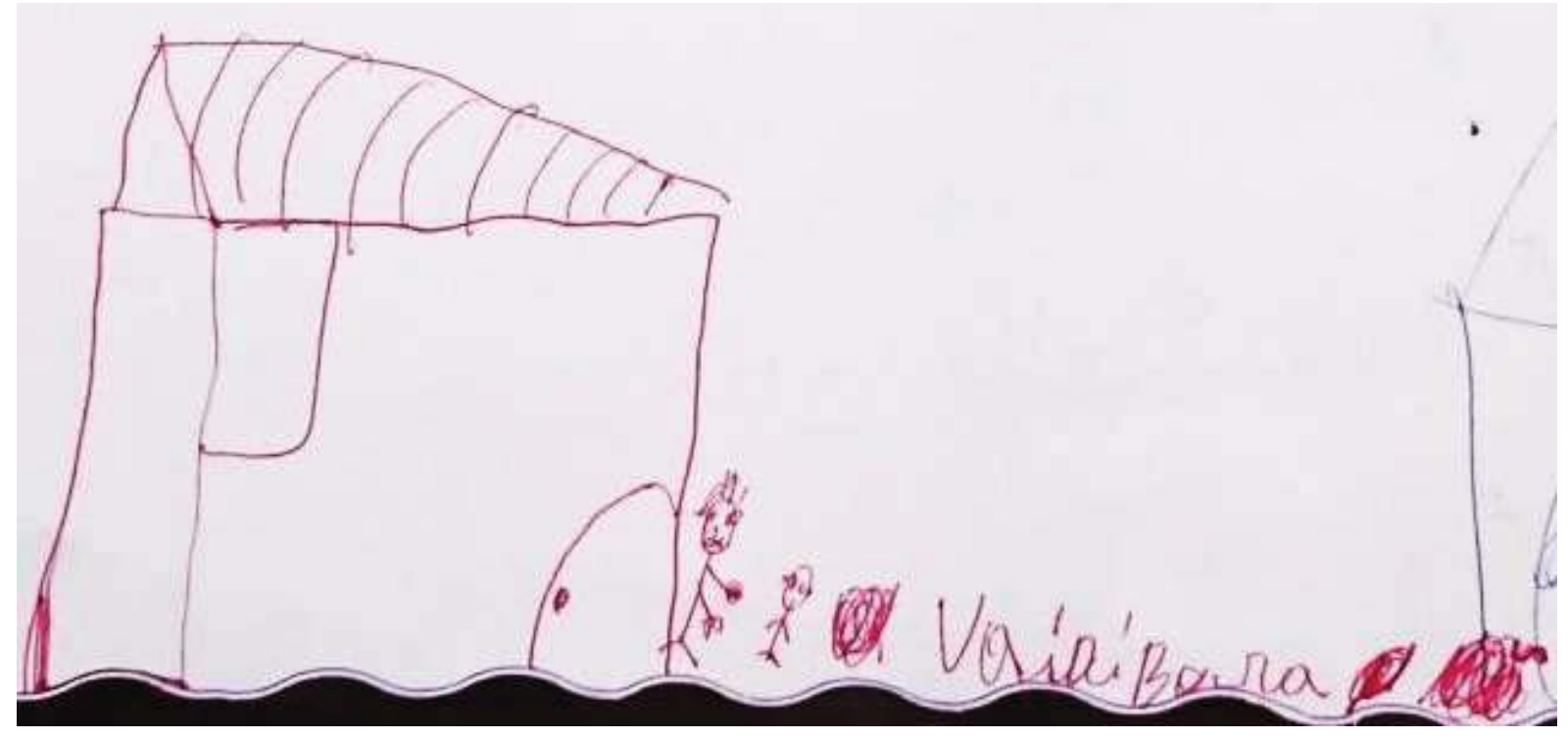

Imagem 10 - Barandão e Pirulito desenhando livremente.

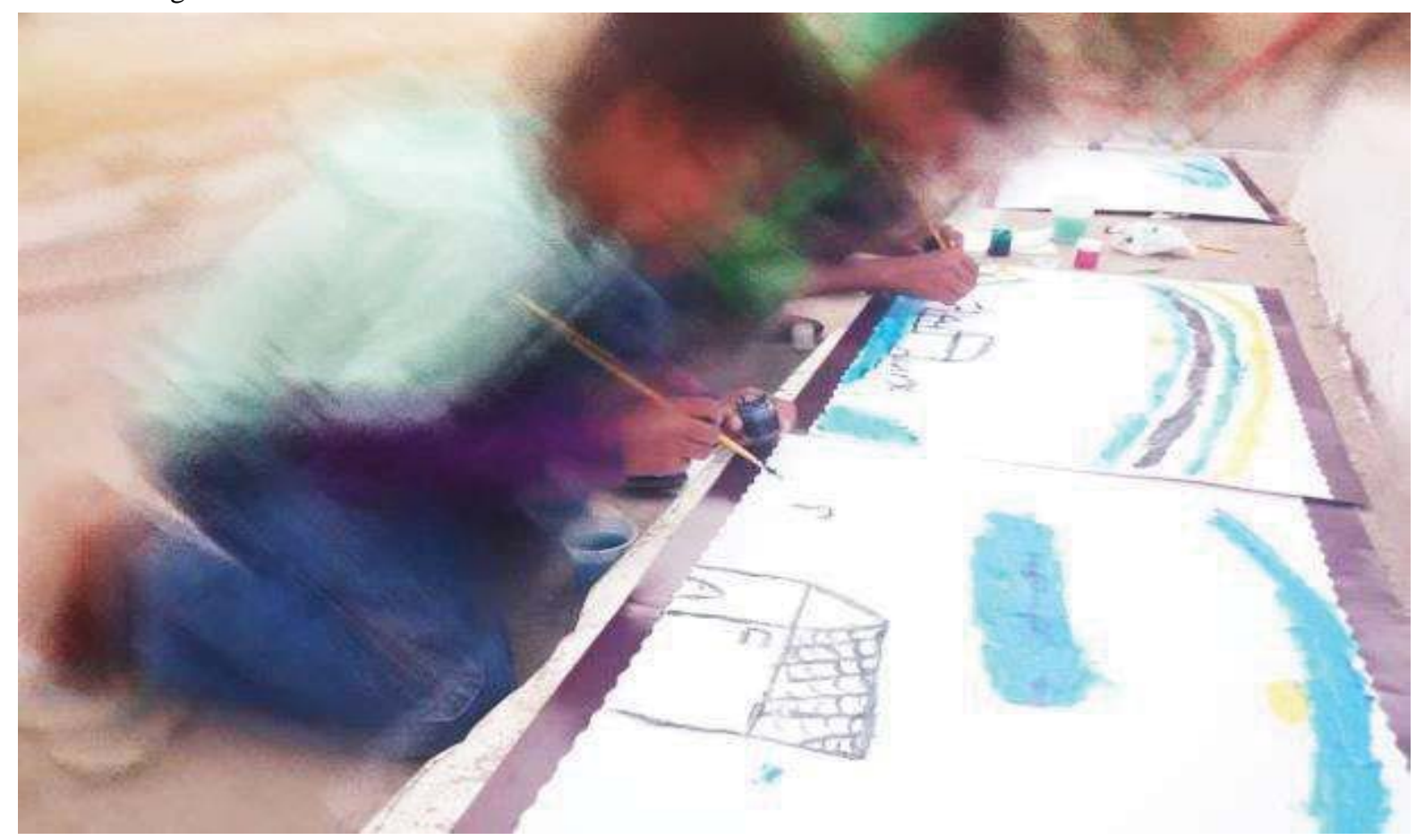

"Surgiu uma concepção seriamente modificada da concepção infantil (...) uma mente buscando sentido, criando sentido, preservando sentido e usando sentido; numa palavra - a palavra de Nelson Goodman - construtora do mundo". A partir dessas colocações de Geertz (2001, p. 186) nos aproximamos do que o autor propõe enquanto antropologia do sensível, de maneira mais ampla destaco para essa pesquisa do sensível, dessa proximidade em relação ao outro ocorrida com tranquilidade, buscando perceber aspectos que estão para além do que as palavras e os gestos dizem, mas percebendo e sentindo o silêncio. 
A perspectiva da liberdade e da satisfação está presente em todo ser humano que de alguma forma está aprisionado, seja essa prisão identificada enquanto um pensamento, uma relação, uma pessoa, um trabalho, um estilo de vida, etc, mas o que interessa nesse momento é que a rua torna-se uma porta para fugir do que nos aprisiona, no caso das crianças é uma porta para um grande espaço a ser explorado, um mundo cercado de possibilidades, que não está ligado a ideia de bom ou ruim, mas um espaço de possibilidades. Um espaço que elas, em grupo ou sozinhas podem brincar livremente e ser criança de acordo com as possibilidades existente em cada espaço.

A rua também é um espaço de aprendizagem e sua leitura deve ser (re)constituída para possibilitar oportunidades a essas crianças, a falta de espaços de divertimento público somente soma-se a falta de outras questões sociopolíticas em que estamos mergulhados. A cada dia é preciso, para essas crianças, reinventar os espaços públicos, fazer deles um ambiente para auxiliar na renda familiar, assim como organizá-lo em sua imaginação como um espaço para brincar, interagir com outras crianças e se divertir.

Cohn (2005, p. 32) pontua a respeito dos trabalhos com crianças em situação de rua, a partir da pesquisa antropológica, que as crianças "têm um papel ativo não só na construção de laços e relações sociais como na elaboração de uma imagem, uma identidade, para si e para os outros", nos é apresentado aqui o fluxo contínuo do movimento dessas crianças e de sua estruturação sociocultural enquanto cidadã, sujeito ativo de uma sociedade líquida, nos parâmetros de Bauman (2001).

\section{CONSIDERAÇÕES FINAIS}

Em sociedade costumamos julgar situações com base naquilo que culturalmente aprendemos que é certo ou errado e na maioria das vezes desconsideramos o outro. As dificuldades em escutar o outro com o propósito de entendê-lo torna-se cada vez mais presente entre nós, esse movimento de escuta para a compreensão foi realizado durante a pesquisa, pois os problemas sociais não existem por culpa das crianças e sim pela má organização da sociedade como um todo e principalmente devido ao não compromisso dos adultos que resulta na falta de uma organização política adequada a todos os cidadãos.

Entender as crianças em situação de rua é entender dinâmicas de invisibilidade de sujeitos que nem sempre são respeitados em suas singularidades. O que foi possível vislumbrar na breve incursão em meio ao emaranhado subjetivo que envolve o tema, são redes de relações complexas que são acionadas pelas crianças como forma de sobrevivência 
social e de aprendizado para a vivência cotidiana. Estar na rua é aprender a lidar com várias formas de violências cotidianas, mas é também uma forma de aprender formas de sociabilidade que garantem a vivência nas ruas.

\section{REFERÊNCIAS}

ABREU, Waldir Ferreira. O Trabalho de Socialização de Meninos de Rua em Belém do Pará: Um Estudo sobre a República do Pequeno Vendedor. 2010. 245 f. Tese (Doutorado em Ciências Humanas e Educação) - Pontifícia Universidade Católica do Rio de Janeiro, Departamento de Educação, Rio de Janeiro, 2010.

AMADO, Jorge. Capitães da Areia. São Paulo: Companhia das Letras, 2009.

ARIÈS, P. História social da infância e da família. Tradução: D. Flaksman. Rio de Janeiro: LCT, 1978.

BAUMAN, Zygmut. Modernidade Liquida. Rio de Janeiro: Jorge Zahar, 2001.

CARVAlho, A. M. A.; MAgAlhãeS, C. M. C.; PONTES, F. A. R.; BICHARA, I. D. (Ed.). Brincadeira e cultura: viajando pelo Brasil que brinca. São Paulo: Casa do Psicólogo, 2003.

COHN, Clarice. Antropologia da Criança. Rio de Janeiro: Zahar, 2005.

CORSARO, William. Entrada no Campo, Aceitação e Natureza da Participação nos Estudos Etnográficos com Crianças Pequenas. In Educação e Sociedade. Campinas, vol. 26, n. 91, p. 443-464, Maio/Ago. 2005.

CEBRID. Levantamento Nacional sobre o Uso de Drogas entre Crianças e Adolescentes em situação de rua nas 27 capitais brasileiras. São Paulo, 2003.

FREIRE, Paulo. Educadores de Rua uma abordagem crítica: alternativas de atendimento aos meninos de rua. UNICEF, julho, 1989.

GRAUE, M. Elizabeth \& WALSH, Daniel J. Investigação etnográfica com crianças. Lisboa: Gulbenkian, 2003.

GEERTZ, Clifford. Nova Luz sobre a antropologia. Rio de Janeiro: Zahar, 2001.

MACEDO, Ana Gabriela \& AMARAL, Ana Luísa. Dicionário da Crítica Feminista. Edições afrontamentos, 2005.

OLIVEIRA, Walter Ferreira. Educação social de rua: bases históricas, políticas e pedagógicas. Acesso: http://www.scielo.br/pdf/hcsm/v14n1/07.pdf. Acessado em: $18 / 12 / 2014$.

OAKLANDER, Violet. Descobrindo crianças: a abordagem gestáltica com crianças e adolescentes. $17^{\text {a }}$ ed. São Paulo: Summus, 1980. 